\title{
Blood lactic acid increased by hydroxyurea in a leukemia patient
}

Jing Hu, Can Luo

Department of Pharmacy, First Affiliated Hospital of Nanjing Medical, Nanjing, China

Submitted: 18 September 2018

Accepted: 31 May 2019

Arch Med Sci 2020; 16 (6): 1487-1490

DOI: https://doi.org/10.5114/aoms.2019.86188

Copyright @ 2019 Termedia \& Banach

Lactic acidosis or hyperlactatemia is a common symptom in patients with sepsis or hypovolemia. The generation of lactate needs pyruvic acid that is catalyzed by lactate dehydrogenase (LDH) in the cytosol. With sufficient oxygen supply, pyruvic acid from glucose can be transported into mitochondria and completely decomposed. As a result, anaerobic glycolysis of glucose is increased and more lactic acid is produced at low oxygen levels, which is known as hypoxia. Correspondingly, hyperlactatemia occurs when the balance between generation and conversion is broken. The higher the lactate level is, the worse is the outcome [1]. Hyperlactatemia in patients in the intensive care unit (ICU) is mainly related to hypoperfusion and hypoxia, although other causes including some usual drugs and hematological malignancies may also cause hyperlactatemia. Despite increasing public awareness and advanced detection methods in place, drug-induced lactic acidosis is often overlooked. The treatment of hyperlactatemia is dependent on the cause. The wrong treatment will not only delay the treatment or even cause death, but also increase the additional economic burden. So understanding pharmacological factors of hydroxyurea causing hyperlactatemia in the condition could lead to avoiding the wrong treatment. We report a case of an elderly man who falsely presented with elevated blood lactic acid due to treatment with hydroxyurea.

A 62-year-old male patient was hospitalized because of coughing, expectoration, shortness of breath and large ecchymosis in the skin for 1 week. His past history and medication history had no abnormalities. At admission, the main haematological parameters from peripheral blood showed thrombocytopenia and erythropenia. The main haematological parameters were as follows: hemoglobin $46 \mathrm{~g} /$, platelet count $15 \times 10^{9} / \mathrm{l}$, leucocyte count $22.74 \times 10^{9} /$ I (neutrophils $4 \%$, lymphocytes $13 \%$, monocytes $13 \%$ ) and immature cells accounting for $70 \%$. A bone marrow puncture was performed and the patient was finally diagnosed with acute myeloid leukemia (AML, M3). Consequently, leukemia control treatment ((hydroxyurea (1 g, three times a day), retinoic acid (10 mg, twice a day) and prednisone (10 $\mathrm{mg}$, three times a day)) was started at the first day of admission on July 31 and August 1 . However, the patient was admitted to our intensive care unit for severe pneumonia. Leukemia control treatment (hydroxyurea $1 \mathrm{~g}$ three times a day, retinoic acid $10 \mathrm{mg}$ twice a day and prednisone $10 \mathrm{mg}$ three times a day) was resumed on the third day of admission on August 4.

At the moment of admission, a computed tomography scan showed that the pulmonary inflammation had significantly progressed and the

\author{
Corresponding authors: \\ Jing Hu \\ Can Luo \\ Department \\ of Pharmacy \\ First Affiliated \\ Hospital of \\ Nanjing Medical \\ 210000 Nanjing, China \\ E-mail: hujingjsph@163.com, \\ luocan@jsph.org.cn
}


chest film had patchy and cloudy dense areas. Concurrent medications included imipenem-cilastatin sodium $2 \mathrm{~g} / 8 \mathrm{~h}$ and voriconazole $200 \mathrm{mg} / 12 \mathrm{~h}$. Furthermore, sulfamethoxazole/trimethoprim $0.96 \mathrm{~g} /$ $6 \mathrm{~h}$ was also prescribed because Pneumocystis carinii pneumonia cannot be ruled out in immunosuppressed patients who experience repeated fever during treatment. Gradually his lung infection was controlled and there was no fever. However, elevated blood lactic acid developed immediately after starting leukemia treatment on admission and had a certain regularity. Upon admission, the patient's blood lactate acid level was measured once every $8 \mathrm{~h}$, but it was elevated only at 13 o'clock and 21 o'clock (Figure 1). There was no significant increase in blood lactic acid at 6 o'clock, and the range of blood lactate elevation was 2-6 mmol/l, which was accompanied by an increase in urea nitrogen (Table I). However, blood pressure fluctuations remained in the basic normal range, and hemodynamic parameters were essentially stable during treatment without vasoactive drugs. Invasive blood pressure fluctuated in the range $140-180 / 70-100 \mathrm{~mm} \mathrm{Hg}$, heart rate fluctuated in the range $65-100$ beats/min, there were no signs of tissue hypoperfusion, and the condition was not accompanied by organ failure. The pharmacist reviewed the literature and suggested that hydroxyurea could not be excluded and restoring tissue perfusion was not necessary. Hyperlactatemia was basically stable with the course of hydroxyurea during the treatment. The result of the blood test showed the leucocyte count $3.03 \times 10^{9} /$ l (neutrophils 0.749 ), hemoglobin $67 \mathrm{~g} / \mathrm{l}$, platelet count $54 \times 10^{9} / \mathrm{l}$. The patient's pneumonia and leukemia symptoms improved with treatment, and he was transferred to the general ward on the tenth day after admission for further treatment. Unfortunately, family members of the patient abandoned treatment for respiratory failure.

During hospitalization, the most frequent causes of hyperlactatemia were ruled out in our patient. His circulation was stable and he did not require vasoactive drugs. Therefore, the patient did not have tissue hypoperfusion or hypoxia. Nevertheless, hyperlactatemia can also develop due to fermentation of glucose to lactic acid in tumor patients, also known as aerobic glycolysis or the Warburg effect $[2,3]$. According to De Rae's et al. report, high levels of lactate dehydrogenase and spontaneous hypoglycemia can be clues of malignant lactic acidosis because of cell destruction and impaired gluconeogenesis [4]. Furthermore, the lactate dehydrogenase and lactate levels basically followed the same trend, and then decreased to normal levels with leukemia improved or chemotherapy. But our lactate levels continued to increase regularly when the patient's leukemia improved with mature granulocytes gradually becoming normal during chemotherapy (Table II). So the effect of leukemia can also be ruled out. There was no abnormality in liver enzymes, kidney function, or other indicators of tumor lysis syndrome during the course of treatment. Hyperlactatemia was not described as an adverse event of the other concurrent medications.

Eventually, the Naranjo nomogram (7 points, probable) showed a probable correlation between hyperlactatemia and the use of hydroxyurea [5] The patient's blood lactate elevation occurred after the use of hydroxyurea, and the timing of hyperlactatemia was approximately $13.00 \mathrm{~h}$ and $21.00 \mathrm{~h}$ every day. Hydroxyurea was taken three times a day (9-12-18.00 h). The half-life of the drug was 1.9-3.9 h. The time of maximum effect was 1-4 h. Similarly, the elevation of blood lactic acid typically appeared $4 \mathrm{~h}$ after consuming the medication, demonstrating a simultaneous increase in urea nitrogen, which is basically consistent with a case report by Restituto et al. [6]. How ever, clinical treatment is effective, and patients do not experience discomfort or other adverse reactions; therefore, treatment with hydroxyurea was continued.

To the best of our knowledge, few studies have reported the development of hyperlactatemia following hydroxyurea application. Additionally, we also noticed that hydroxyurea may interfere in the

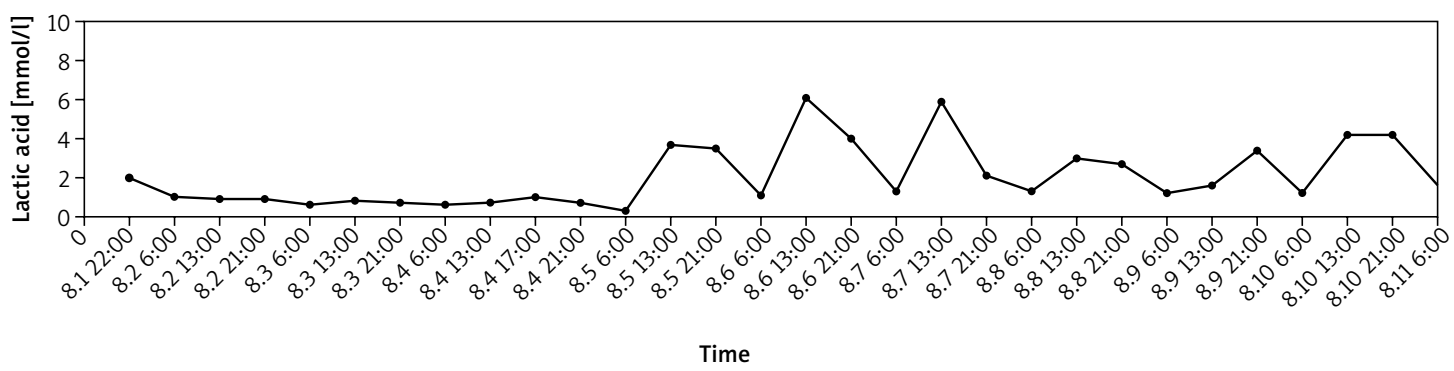

Figure 1. The change in lactic acid value for a 63-year-old Chinese female in patient during his therapy. Hydroxyurea was discontinued on August 1 and resumed on August 4. Lactic acid increased regularly after chemotherapy with a certain relationship with the time of administration of hydroxyurea. The administration time was 9-12$18.00 \mathrm{~h}$ and the time of elevated blood lactate was $13-21.00 \mathrm{~h}$ 


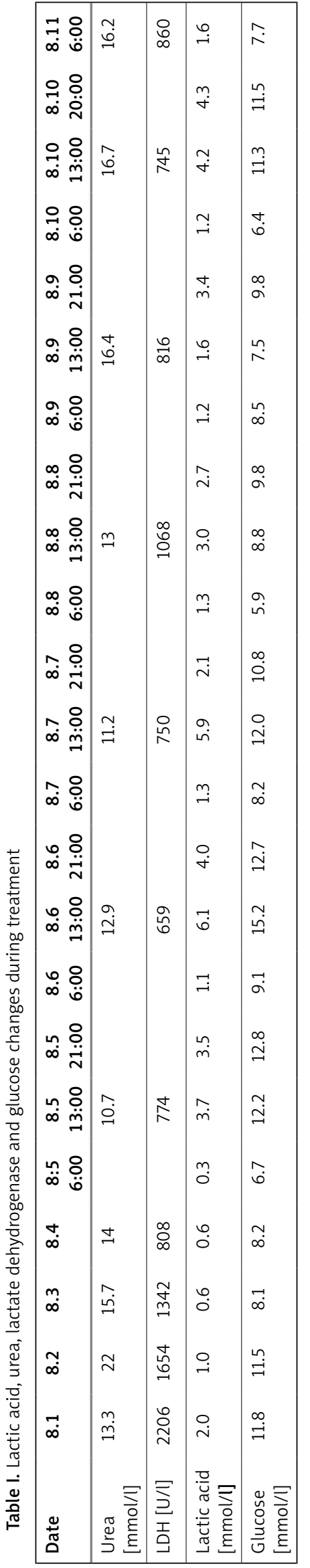

\begin{tabular}{|c|c|c|c|c|c|c|c|c|c|c|}
\hline 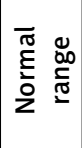 & $\mid \begin{array}{l}0 \\
\dot{9} \\
1 \\
0 \\
\dot{+} \\
\end{array}$ & $\begin{array}{l}n \\
\hat{0} \\
0 \\
1 \\
0 \\
\vdots \\
0\end{array}$ & $\mid \begin{array}{l}\vec{J} \\
b \\
1 \\
\infty \\
-i \\
-i\end{array}$ & 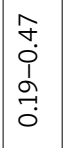 & $\begin{array}{l}\infty \\
0 \\
0 \\
0 \\
m \\
0 \\
0 \\
0\end{array}$ & $\begin{array}{l}0 \\
0 \\
0 \\
0 \\
1 \\
\stackrel{1}{0} \\
0 \\
0\end{array}$ & $\begin{array}{l}\overrightarrow{0} \\
0 \\
0 \\
1 \\
0 \\
0 \\
0\end{array}$ & 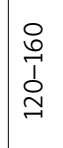 & $\begin{array}{l}\stackrel{8}{0} \\
\hat{1} \\
\grave{o} \\
0\end{array}$ & - \\
\hline$\underset{\infty}{\sim}$ & $\begin{array}{l}\tilde{n} \\
\dot{n}\end{array}$ & $\begin{array}{l}n \\
\hat{\alpha} \\
0\end{array}$ & $\stackrel{\sim}{N}$ & $\stackrel{\sim}{\circ}$ & $\begin{array}{l}\text { Ln } \\
\text { Ọ }\end{array}$ & 0 & 0 & $\hat{6}$ & in & - \\
\hline$\underset{\substack{0 \\
\infty \\
\infty}}{0}$ & $\stackrel{9}{\vec{g}}$ & $\begin{array}{c}\tilde{a} \\
\infty \\
0\end{array}$ & $\hat{\sigma}$ & $\underset{0}{\stackrel{t}{0}}$ & O্. & 0 & 0 & $\ddot{0}$ & $\stackrel{\sim}{m}$ & - \\
\hline$\underset{\infty}{\stackrel{\alpha}{a}}$ & $\begin{array}{l}n \\
\infty \\
\infty \\
\end{array}$ & t. & 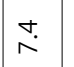 & $\stackrel{\sim}{0}$ & $\stackrel{亏}{0}$ & $\underset{0}{0}$ & 0 & 8 & $m$ & $\stackrel{\vec{\pi}}{0}$ \\
\hline $\begin{array}{l}\infty \\
\infty \\
\infty\end{array}$ & 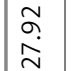 & $\vec{b}$ & مo & ㄱ: & $\overrightarrow{0}$ & 0 & 0 & 8 & $\stackrel{\infty}{\circ}$ & $\underset{0}{\Delta}$ \\
\hline$\hat{\infty}$ & 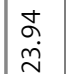 & f̊ & $\stackrel{\stackrel{n}{\sim}}{\exists}$ & $\underset{\sim}{\tilde{O}}$ & F & 0 & 0 & $\approx$ & $\stackrel{t}{m}$ & $\underset{1}{\approx}$ \\
\hline$\infty_{\infty}^{\circ}$ & 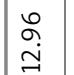 & în & $\stackrel{\circ}{\stackrel{0}{r}}$ & $\underset{⿱ t}{\stackrel{J}{0}}$ & $\begin{array}{l}\stackrel{n}{0} \\
\stackrel{0}{0}\end{array}$ & 0 & 0 & 文 & そ & $\begin{array}{l}\overrightarrow{1} \\
0\end{array}$ \\
\hline $\mid \begin{array}{l}n \\
\infty \\
\infty\end{array}$ & 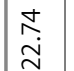 & $\begin{array}{l}0 \\
\stackrel{1}{0}\end{array}$ & $\stackrel{\circ}{\text { r. }}$ & $\begin{array}{l}0 \\
0 \\
0\end{array}$ & $\stackrel{2}{\stackrel{2}{0}}$ & 0 & 0 & $\infty$ & $\stackrel{\infty}{\text { in }}$ & $\begin{array}{l}\substack{n \\
0} \\
\end{array}$ \\
\hline${ }_{\infty}^{+}+\infty$ & 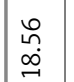 & $\stackrel{m}{0}$ & $\stackrel{\sim}{\sim}$ & $\stackrel{n}{0}$ & $\overrightarrow{0}$ & 0 & 0 & 8 & $\widetilde{0}$ & $\mid \begin{array}{l}\tilde{D} \\
0 \\
0\end{array}$ \\
\hline$\left.\right|_{\infty} ^{m}$ & 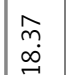 & oे & & $\stackrel{n}{\stackrel{n}{0}}$ & F & 0 & 0 & $\overrightarrow{0}$ & $\stackrel{\text { m }}{ }$ & $\begin{array}{l}n \\
0 \\
0\end{array}$ \\
\hline$\vec{\infty}$ & f̀. & $\stackrel{2}{\stackrel{2}{0}}$ & 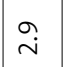 & 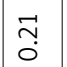 & $\overrightarrow{0}$ & 0 & 0 & 우 & $\stackrel{\sim}{2}$ & 苦 \\
\hline$\vec{m}$ & $\begin{array}{l}\infty \\
\infty \\
\infty \\
\infty \\
\end{array}$ & Oे & $\underset{0}{N}$ & $\stackrel{m}{\dddot{n}}$ & $\stackrel{m}{0}$ & 0 & 0 & o & $\stackrel{\curvearrowleft}{\sim}$ & $\hat{o}$ \\
\hline 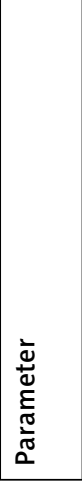 & 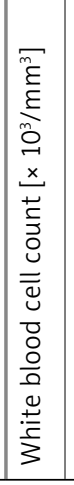 & 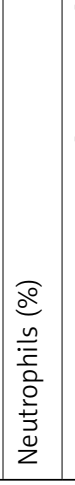 & 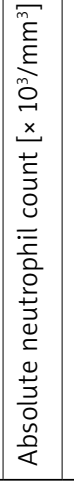 & 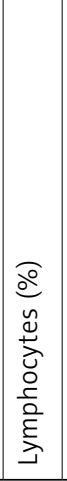 & 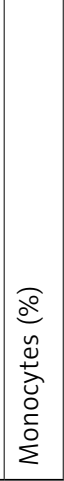 & 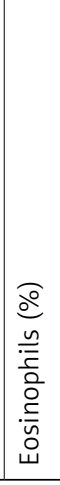 & 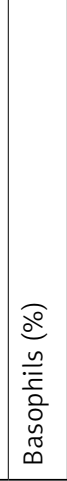 & 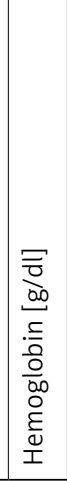 & 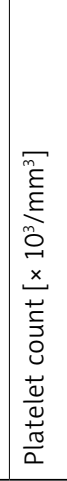 & 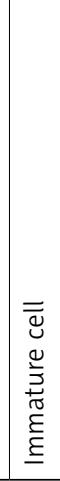 \\
\hline
\end{tabular}


determination of lactic acid levels [6]. An increase in lactic acid could be observed in healthy volunteers after taking hydroxyurea. The levels of hydroxyurea can reach $0.1-0.5 \mathrm{mmol} / \mathrm{l}$ after administration of $500 \mathrm{mg}$ twice a day [7]. At a similar exogenous level, the level of urea, uric acid and lactic acid could be increased by $43 \%, 5 \%$ and $6 \%$, respectively [6]. Therefore, the elevated lactic acid level of hydroxyurea is not too high, accompanied by elevated urea, and the level will decrease with the metabolism of hydroxyurea. This feature is consistent with our case report. The exact mechanisms of hyperlactatemia found in hydroxyurea have not been well studied. Hydroxyurea, a ribonucleotide reductase inhibitor, can increase levels of urea and uric acid due to inhibition of DNA synthesis. However, hyperlactatemia has not been alleviated by improvement of the condition. After then hydroxyurea is thought to have a similar structure to lactic acid, suggesting that lactate dehydrogenase, which regulates the levels of lactic acid, may react with the drug, providing falsely high results [8]. This is confirmed when hydroxyurea is added exogenously; levels of lactic acid are higher than before. From the current point of view its mechanism may involve lactic acid metabolism as a structural analogue. But for hyperlactatemia, there is no standard-of-care treatment of hydroxyurea-induced hyperlactatemia. During therapy, patient status and lactate levels should be regularly monitored by reference to linezolid and other drugs. From the current possible mechanism, the pseudo-elevated hyperlactatemia does not affect the physiological state of the patient and does not require withdrawal and intervention. Whether withdrawal will reduce lactate acid level and give intercurrent life support will be confirmed in future studies $[9,10]$.

In conclusion, hyperlactatemia induced by hydroxyurea is uncommon and rarely reported. This report is the first to show that hydroxyurea significantly increases blood lactic acid concomitantly with urea nitrogen. Hypoperfusion and hypoxia may be the main causes of hyperlactatemia in the ICU. Elevated blood lactate acid levels in patients with leukemia are usually related to disease, but hydroxyurea-induced lactic acidosis should be suspected only after exclusion of other, more common, causes of lactic acidosis such as hypoxemia, anemia or low cardiac output. It is still necessary to pay attention to the influence of drugs to avoid the effect of elevated blood lactic acid on clinical decisions.

\section{Conflict of interest}

The authors declare no conflict of interest.
References

1. Kraut JA, Madias NE. Lactic acidosis. N Engl J Med 2014; 371: 2309-19.

2. Pillai SR, Damaghi M, Marunaka Y, et al. Causes, consequences, and therapy of tumors acidosis. Cancer Metastasis Rev 2019; doi: 10.1007/s10555-019-09792-7.

3. Sayyed AH, Aleem A, Al-Katari MS, et al. Acute lymphoblastic leukemia presenting with liver infiltration and severe lactic acidosis. Am J Case Rep 2018; 17: 453-7.

4. De Raes EA, Benoit DD, Depuydt PO, et al. Early recognition of malignant lactic acidosis in clinical practice: report on 6 patients with haematological malignancies. Acta Clin Belg 2012; 67: 347-51.

5. Naranjo CA, Busto U, Sellers EM, et al. A method for estimating the probability of adverse drug reactions. Clin Pharmacol Ther 1981; 30: 239-45.

6. Restituto P, Mugueta C, Alegre E, et al. Analytical interference of hydroxyurea in the determination of urea, uric acid, and lactic acid. Anal Biochem 2006; 357: 147-9.

7. Rodriguez GI, Kuhn JG, Weiss GR, et al. A bioavailability and pharmacokinetic study of oral and intravenous hydroxyurea. Blood 1998; 91: 1533-41.

8. Opacic N, Zorc B, Cetina M, et al. Synthesis and X-ray crystal structure study of the hydroxyurea and hydantoin derivatives of L-valine. Peptide Res 2005; 66: 85-93.

9. Santini A, Ronchi D, Garbellini M, et al. Linezolid-induced lactic acidosis: the thin line between bacterial and mitochondrial ribosomes. Expert Opin Drug Saf 2017; 16: 833-43.

10. Krajčová A, Waldauf P, Anděl M, Duška F. Propofol infusion syndrome: a structured review of experimental studies and 153 published case reports. Crit Care 2015; 19: 398 . 